\title{
Anemia in Spontaneously Type 2 Diabetic Rats With Renal Impairment
}

\author{
Stella Maris Daniele ${ }^{\mathrm{a}}$, Juan Carlos Picena ${ }^{\mathrm{b}}$, Hector Rodriguez ${ }^{\mathrm{a}}$, Silvana Marisa Montenegro ${ }^{\mathrm{b}, \mathrm{c}}$, \\ Maria Cristina Tarres ${ }^{b, c}$, Stella Maris Martinez ${ }^{b, c, d}$
}

\begin{abstract}
Background: The eSS rats display a mild non obese type 2 diabetic syndrome with an insulin resistant state characterized by hyperglycemia, dyslipidemia and hyperinsulinemia. During the first year, eSS male rats exhibit proteinuria as well as alterations in glomerular filtration.
\end{abstract}

Methods: In this study, some hematological characteristics were evaluated in 12 month-old eSS males compared to eumetabolic Wistar rats, and the renal histology was also studied.

Results: The diabetic rats were found to have fewer erythrocytes and lower values of hemoglobin. In eSS rats, peripheral blood smears showed immature erythrocytes with polychromatophilia and the presence of erythroblasts was also verified. Thickening of the glomerular basement membrane, areas of tubular dilatation and protein cylinders were observed in kidneys of diabetic animals.

Conclusions: Our results suggest that eSS rats develop anemia because of complex influences of metabolic disturbances and diabetic renal damage and that it might provide new opportunities for studying the pathogenesis of this relevant complication of type 2 diabetics.

Keywords: Anemia; Type 2 diabetes; Renal disease; Rats

\section{Introduction}

Anemia is the most common blood disorder in diabetic patients and a significant risk factor for diabetic complications

\footnotetext{
Manuscript accepted for publication October 1, 2012

${ }^{\text {a }}$ School of Biochemistry Sciences, National University of Rosario, Rosario, Argentina

${ }^{\mathrm{b}}$ School of Medical Sciences, National University of Rosario, Rosario, Argentina

${ }^{\mathrm{c}}$ Research Council, National University of Rosario, Rosario, Argentina

${ }^{\mathrm{d} C}$ Corresponding author: Stella Maris Martinez, Catedra de Biologia,

Facultad de Ciencias Medicas, Universidad Nacional de Rosario, Santa

Fe 3100, Rosario, Argentina. Email: smartinez948@yahoo.com.mx
}

doi: http://dx.doi.org/10.4021/jem122w in terms of morbidity, mortality and health care costs [1]. Even though a high incidence of anemia was observed in diabetics without renal impairment especially in those aged and with poor glycemia control [2], anemia is more frequent and more severe in diabetic patients with chronic kidney disease [3-6], being possible to correlate decreased hemoglobin levels with the severity of renal failure $[6,7]$.

Previous studies carried out in the facilities our laboratory led to demonstrate a mild non obese diabetic syndrome in eSS rats with an insulin resistant state characterized by hyperglycemia, dyslipidemia and hyperinsulinemia with higher expression in males that worsen as they become older $[8,9]$. Between 6 to 12 months of age, eSS rats usually develop raising proteinuria and at 12 months of age exhibit lesions of diabetic nephropathy $[10,11]$.

In consequence, taking advantage of the naturally slow progress of the metabolic derangement in the eSS rats and the consequent long-life-span, we decided to investigate whether 12-month old eSS male rats develop hematological alterations.

\section{Materials and Methods}

\section{Animals}

Twelve 12-month-old eSS male rats and eleven eumetabolic Wistar (W) rats paired by age were studied. eSS is an inbred rat maintained in the School of Medicine, Rosario University at Rosario, Argentina. Wistar came from the animal breeding facilities in the School of Biochemical Science, Rosario University. Breeding conditions were the same for all the animals, including temperature regulation $\left(24^{\circ} \mathrm{C}\right)$ and lightdarkness cycles as well as the artificial air exchange. In all the cases, the individuals had remained housed since they were 21 days old, in hanging collective cages. All animals were fed on a complete commercial diet, special for laboratory rats, and water was ad libitum. These experimental conditions were maintained until the animals were euthanized.

\section{Experimental procedures}

After 10-hs overnight fast, all animals were weighed and 


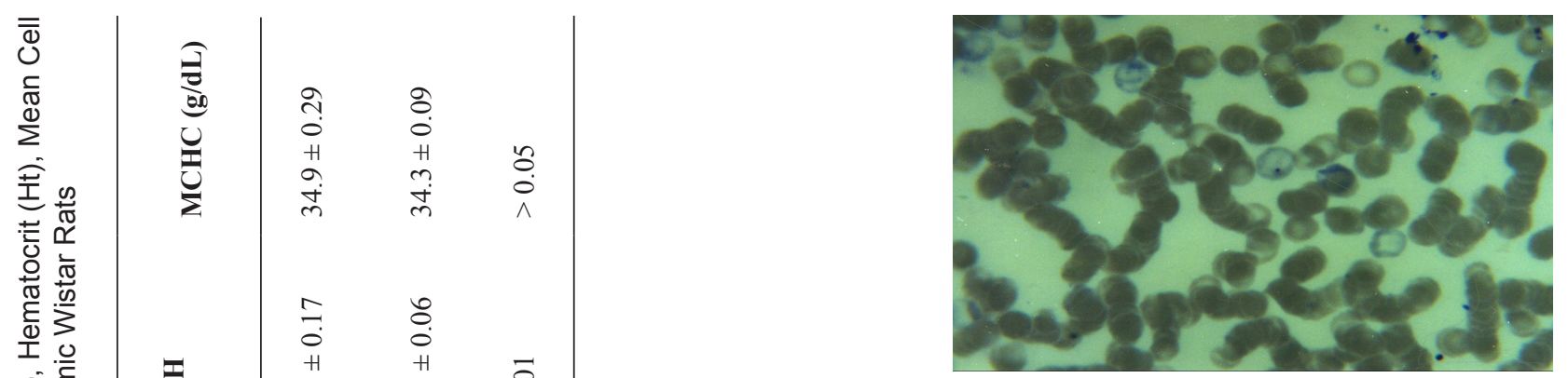

Figure 1. Blood smear of a 12-month old eSS diabetic showing polychromasia, a Howell-Jolly body (center) and Rouleaux formation. May-Grünwald-Giemsa stain. $100 \times$.

exsanguinated by cardiac puncture under deep sodium thiopental anesthesia. The animals were sacrificed by this blood sampling. Part of the blood was collected into tubes pretreated EDTA and used as specimen for hematological analyses which required whole blood. Red blood cell count $\left(\mathrm{RBC} / \mathrm{mm}^{3}\right)$, white blood cell count $\left(\mathrm{WBC} / \mathrm{mm}^{3}\right)$ and platelet count $\left(\mathrm{Pt} / \mathrm{mm}^{3}\right)$ as well as the hematocrit $(\mathrm{Ht} \%)$ and the hemoglobin concentration $(\mathrm{Hb} ; \mathrm{g} / \mathrm{dL})$ were obtained using a multi-parameter hematology analyzer (CELL-DYN 1400 ABBOTT). For the platelet count, blood sample was diluted 1/10. Mean cell volume (MCV; femtoliters), mean cell hemoglobin (MCH; pg) and mean cell hemoglobin concentration $(\mathrm{MCHC} ; \mathrm{g} / \mathrm{dL})$ were also determined. A second aliquot of blood was allowed to clot and centrifuged to obtain hemolysis-free serum which was used for determinations of fasting glycemia $(\mathrm{G} 0 ; \mathrm{g} / \mathrm{dL})$ and fructosamine levels (FH2; $\mu \mathrm{mol} / \mathrm{L}$ ). Using a fresh blood drop taken from the tail tip before cardiac puncture, red blood cells on a blood smear were stained with May-Grünwald-Giemsa (Sigma) for morphological analysis.

Immediately after death, both kidneys were removed in six eSS and six Wistar male rats. Sections of renal tissue were fixed in 10\% neutral-buffered formalin for 24 hours, embedded in paraffin, cut into sections of $4 \mu \mathrm{m}$ thick, stained with

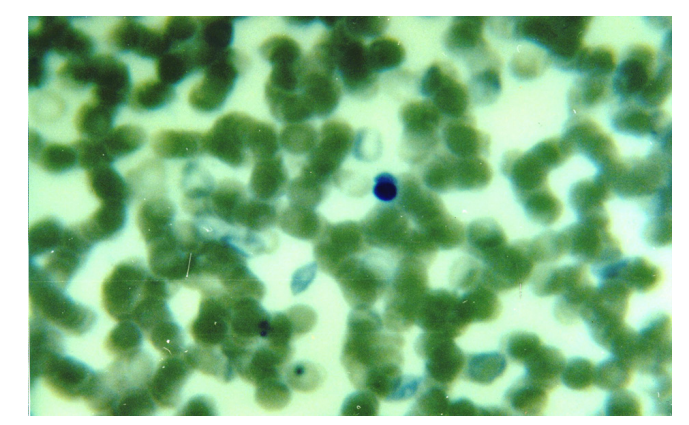

Figure 2. Blood smear of a 12-month eSS diabetic showing an erythroblast (center). May-Grünwald-Giemsa stain. $100 \times$. 


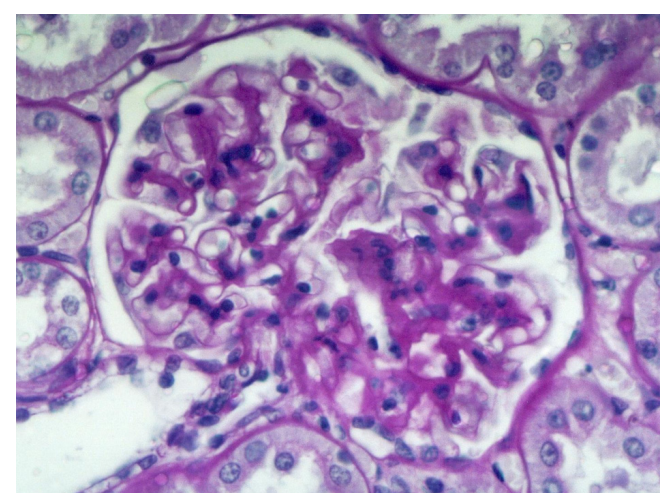

Figure 3. Mild diffuse mesangial thickening of the glomerular basement membrane (12-month old eSS male). HE and Periodic acid-Schiff (PAS) stain. $300 \times$.

hematoxylin-eosin (HE) and Periodic Acid-Schiff (PAS), and examined by light microscopy in a blinded fashion.

\section{Statistical analysis}

The results are presented as the mean \pm 1 standard error of mean (SD). Statistical significance was determined by Student's test. $\mathrm{P}$ value less than $0.05(\mathrm{P}<0.05)$ was accepted as statistically significant.

\section{Ethical considerations}

All experimental procedures presented in this study were approved by the Bioethics Commission of School of Medicine, which assures adherence to the standards by the Guide for the Care and Use of Laboratory Animals.

\section{Results}

As seen in Table 1, eSS rats displayed substantially higher levels of G0 and FH2 and could be considered as being severely hyperglycemic, according to DeFronzo et al $(>140$ $\mathrm{mg} / \mathrm{dL}$ ) [12] whereas Wistar rats remained euglycemic. Table 1 also indicates that diabetic rats presented higher levels of $\mathrm{RBC}, \mathrm{Hb}$ and $\mathrm{Ht}$ than those of controls. MCV and MCHC did not differ between groups while $\mathrm{MCH}$ was higher in eSS than in $\mathrm{W}$ rats.

$\mathrm{WBC} / \mathrm{mm}^{3}$ was lower in eSS than in $\mathrm{W}(5,175 \pm 528$ vs. $7,280 \pm 633 ; \mathrm{P}<0.05)$ while $\mathrm{Pt} / \mathrm{mm}^{3}$ was higher $(960 \pm 5.6$ vs. $870 \pm 3.6 ; \mathrm{P}<0.001)$. In the eSS rats leukocyte formula, significant higher neutrophil count $(41.3 \pm 2.5 \%$ vs. $19.2 \pm$ $0.3 \% ; \mathrm{P}<0.001)$ and eosinophil count $(3 \pm 0.45 \%$ vs $1.4 \pm$ $0.7 \% ; \mathrm{P}<0.05)$ were noted as compared to W. A minor lymphocyte count $(54 \pm 2.8 \%$ vs. $77.6 \pm 3.3 \%$; $\mathrm{P}<0.001)$ was noticeable in eSS rats.

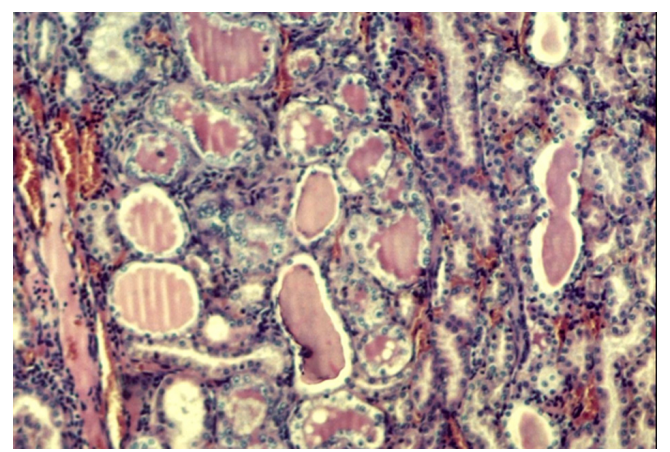

Figure 4. Moderate tubular dilatation with atrophic epithelium, containing proteinaceous cylinders. HE stain. $100 \times$.

In eSS rats, the May-Grünwald-Giemsa-stained blood smears showed polychromasia, presence of erythroblasts and Howell-Jolly bodies as well as enhanced Rouleaux formation. The occurrence of erythroblasts in peripheral blood was quantified in eSS $(1.17 \pm 0.34)$ but it was never verified in Wistar eumetabolic controls (Fig. 1, 2).

Histological examination of kidney of eSS rats revealed glomeruli with diffuse thickness increase of mesangial tissue and a certain amount of small glomeruli was also detected; areas of markedly atrophic and dilated tubules containing acidophilic proteinaceous material were also observed (Fig. $3,4)$ Neither tubular nor glomerular lesions were detected in any Wistar controls.

\section{Discussion}

The anemia of diabetic eSS rats is evidenced by the lower values of the hemoglobin concentration, the hematocrit and the red blood cell when compared to the euglycemic controls that could be related to the chronic metabolic perturbances and the deterioration of renal function of these rats.

Between 6 to 12 months of age, eSS males develop raising albuminuria and impaired glomerular filtration [9]. In diabetics, declining hemoglobin concentration is common among those patients with declining renal function and urinary albumin excretion $[13,14]$. The anemia may result from diverse mechanisms, principally associated to both deficiency and hyporesponsiveness to erythropoietin [15].

In eSS rats, the finding of erythroblasts, polychromatophilia and the presence of Howell-Jolly bodies suggest a compensatory attempt that fails to restore the normal values. Since it has been demonstrated that fragility of red blood cells is increased in diabetic patients due to non-enzymatic glycation of proteins [16, 17], attention should be exerted in the elevated $\mathrm{FH} 2$ values verified in eSS rats indicating the chronic course of the hyperglycemia. The enhanced Rouleaux formation observed in eSS smears could indicate the 
occurrence of hemorheological disorders in the hyperglycemic rats such as the increased erythrocyte adhesiveness and aggregation demonstrated in diabetic patients with poor glycemic control [18].

Because oxidative stress has been identified as the possible cause for producing anemia among diabetics without nephropathy [19], attention should be exerted in the statistical correlation between degree of hyperglycemia, high level of lipidic peroxides and decreased antioxidant defenses verified in eSS rats [20]. An excessive eryptosis related to the oxidative imbalance has been reported in type 2 diabetes patients [21]. Several stressors, including oxidative stress, triggered the red blood cells injury and the resulting eryptosis favors the development of anemia [22, 23]. We suggest that in eSS rats the oxidative stress lead to anemia by impairing the maintenance of erythrocytes. The chronic kidney disease, as it was demonstrated in the eSS rats, would increase the oxidative damage, the red cell fragility and the apoptotic erythrocyte death [24].

The eSS rats had also a significantly lower number of white cells than in controls. Differential count also showed a pattern of lymphopenia and neutrophilia as was reported in critically ill hyperglycemic patients $[25,26]$. These white blood cell changes possibly contribute to the increased susceptibility to infection reported for the eSS rats [27].

The high platelet count verified in the eSS animals might indicate an advanced state of their pathology because thrombocytosis has been detected in diabetic and non diabetic end-stage renal patients [28]. This has also been detected in states of diabetic ketoacidosis [29]. Notwithstanding the renal lesions verified in these eSS rats as well as the high mortality already described in this line during second year of life [30], more studies will be necessary to clarify these findings.

Though new experiments could be undertaken to brighten the genesis and evolution of the hematological alterations in spontaneously diabetic eSS rats, we conclude that the anemia occurrence could be useful to study the interactions between chronic hyperglycemia and diabetic nephropathy, involved in the genesis of this relevant cause of morbidity and mortality in the diabetic patients.

\section{Grant Support}

Thanks are due to the School of Medicine, Rosario University, for providing financial assistance and to Boehringer Mannheim Lab. and to Wiener Lab., Argentina, for their contribution of commercial kits.

\section{Conflict of Interest}

The authors disclose no conflict of interest.

\section{References}

1. Thomas MC, MacIsaac RJ, Tsalamandris C, Molyneaux L, Goubina I, Fulcher G, Yue D, et al. The burden of anaemia in type 2 diabetes and the role of nephropathy: a cross-sectional audit. Nephrol Dial Transplant. 2004;19(7):1792-1797.

2. Adejumo BI, Dimkpa U, Ewenighi CO, Onifade AA, Mokogwu ThA, Erhabor TA, Ukatu E, Nnatuanya IN. Incidence and risk of anemia in type-2 diabetic patients in the absence of renal impairment. Health. 2012; 4(6):304-308.

3. Mercadal L, Metzger M, Casadevall N, Haymann JP, Karras A, Boffa JJ, Flamant M, et al. Timing and determinants of erythropoietin deficiency in chronic kidney disease. Clin J Am Soc Nephrol. 2012;7(1):35-42.

4. Deray G, Heurtier A, Grimaldi A, Launay Vacher V, Isnard Bagnis C. Anemia and diabetes. Am J Nephrol. 2004;24(5):522-526.

5. Mehdi U, Toto RD. Anemia, diabetes, and chronic kidney disease. Diabetes Care. 2009;32(7):1320-1326.

6. Astor BC, Muntner P, Levin A, Eustace JA, Coresh J. Association of kidney function with anemia: the Third National Health and Nutrition Examination Survey (1988-1994). Arch Intern Med. 2002;162(12):14011408.

7. Bonakdaran S, Gharebaghi M, Vahedian M. Prevalence of anemia in type 2 diabetes and role of renal involvement. Saudi J Kidney Dis Transpl. 2011;22(2):286-290.

8. Martinez SM, Tarres MC, Montenegro S, Milo R, Picena JC, Figueroa N, Rabasa SR. Spontaneous diabetes in eSS rats. Acta Diabetol Lat. 1988;25(4):303-313.

9. Daniele SM, Montenegro SM, Tarres MC, Picena JC, Martinez SM. The eSS rat, a nonobese model of disordered glucose and lipid metabolism and fatty liver. Diabetol Metab Syndr. 2010;2:15.

10. Picena JC, Montenegro SM, D’Ottavio AE,Tarres MC, Martinez SM. A Diachronic Study of Diabetic Nephropathy in Two Autochthonous Lines of Rats to Understand Diabetic Chronic Complications (Chapter 16). In: Recent Advances in the Pathogenesis, Prevention and Management of Type 2 Diabetes and its Complications. Ed. Mark B. Zimering, InTech, pp 283-300, 2011.

11. Peto R. Distorting the epidemiology of cancer: the need for a more balanced overview. Nature. 1980;284(5754):297-300.

12. DeFronzo RA, Bonadonna RC, Ferrannini E. Pathogenesis of NIDDM. A balanced overview. Diabetes Care. 1992;15(3):318-368.

13. Wolf G, Muller N, Hunger-Battefeld W, Kloos C, Muller UA. Hemoglobin concentrations are closely linked to renal function in patients with type 1 or 2 diabetes mellitus. Kidney Blood Press Res. 2008;31(5):313-321.

14. Harusato I, Fukui M, Tanaka M, Shiraishi E, Senmaru 
T, Sakabe K, Yamazaki M, et al. Hemoglobin concentration in men with type 2 diabetes mellitus. Metabolism. 2010;59(6):808-813.

15. Thomas S, Rampersad M. Anaemia in diabetes. Acta Diabetol. 2004;41 Suppl 1(S13-17.

16. Kung CM, Tseng ZL, Wang HL. Erythrocyte fragility increases with level of glycosylated hemoglobin in type 2 diabetic patients. Clin Hemorheol Microcirc. 2009;43(4):345-351.

17. Lippi G, Mercadanti M, Aloe R, Targher G. Erythrocyte mechanical fragility is increased in patients with type 2 diabetes. Eur J Intern Med. 2012;23(2):150-153.

18. Cho YI, Mooney MP, Cho DJ. Hemorheological disorders in diabetes mellitus. J Diabetes Sci Technol. 2008;2(6):1130-1138.

19. Waggiallah H, Alzohairy M. The effect of oxidative stress on human red cells glutathione peroxidase, glutathione reductase level, and prevalence of anemia among diabetics. N Am J Med Sci. 2011;3(7):344-347.

20. Daniele SM, Picena JC, Montenegro SM, Tarres MC, Martinez SM. Higado graso no alcoholico en ratas machos de una línea con diabetes genetica. Rev Electron Biomed. 2007;3:29-39.

21. Maellaro E, Leoncini S, Moretti D, Del Bello B, Tanganelli I, De Felice C, Ciccoli L. Erythrocyte caspase-3 activation and oxidative imbalance in erythrocytes and in plasma of type 2 diabetic patients. Acta Diabetol. 2011.

22. Lang F, Lang KS, Lang PA, Huber SM, Wieder T. Mechanisms and significance of eryptosis. Antioxid Redox Signal. 2006;8(7-8):1183-1192.

23. Lang F, Qadri SM. Mechanisms and significance of eryptosis, the suicidal death of erythrocytes. Blood $\mathrm{Pu}$ rif. 2012;33(1-3):125-130.
24. Calderon-Salinas JV, Munoz-Reyes EG, GuerreroRomero JF, Rodriguez-Moran M, Bracho-Riquelme RL, Carrera-Gracia MA, Quintanar-Escorza MA. Eryptosis and oxidative damage in type 2 diabetic mellitus patients with chronic kidney disease. Mol Cell Biochem. 2011;357(1-2):171-179.

25. Jimenez-Ibanez EO, Castillejos-Lopez M, Hernandez A, Gorocica P, Alvarado-Vasquez N. High mortality associated with hyperglycemia, neutrophilia, and lymphopenia in critically ill patients. Tohoku J Exp Med. 2012;226(3):213-220.

26. Celik G, Yontem M, Bilge M, Cilo M, Unaldi M. The relationship between the antioxidant system and anaemia in haemodialysis patients. J Int Med Res. 2011;39(5):19541960.

27. Montenegro S, Tarres MC, Martinez SM, Picena JC, Luciano MI, Molteni O, D’Ottavio AE. Infeccion por peptostreptococcus sp en una colonia de ratas diabeticas. Rev Med Rosario. 1998;64:22-24.

28. Molnar MZ, Streja E, Kovesdy CP, Budoff MJ, Nissenson AR, Krishnan M, Anker SD, et al. High platelet count as a link between renal cachexia and cardiovascular mortality in end-stage renal disease patients. Am J Clin Nutr. 2011;94(3):945-954.

29. Carl GF, Hoffman WH, Passmore GG, Truemper EJ, Lightsey AL, Cornwell PE, Jonah MH. Diabetic ketoacidosis promotes a prothrombotic state. Endocr Res. 2003;29(1):73-82.

30. Martinez SM, Tarres MC, Picena JC, Montenegro SM, Gagliardino JJ, Gomez Dumm CL, D’Ottavio AE, Naves A, et al. eSS rat, an animal model for the study of spontaneous non-insulin-dependent diabetes. Lessons from animal diabetes IV. Ed E Shafrir, Smith Gordon, London, pp 75-90, 1993. 